\title{
LAS UNIONES CONVIVENCIALES EN LA NUEVA LEGISLACIÓN CIVIL ARGENTINA
}

\section{José Vicente Andrade Otaiza}

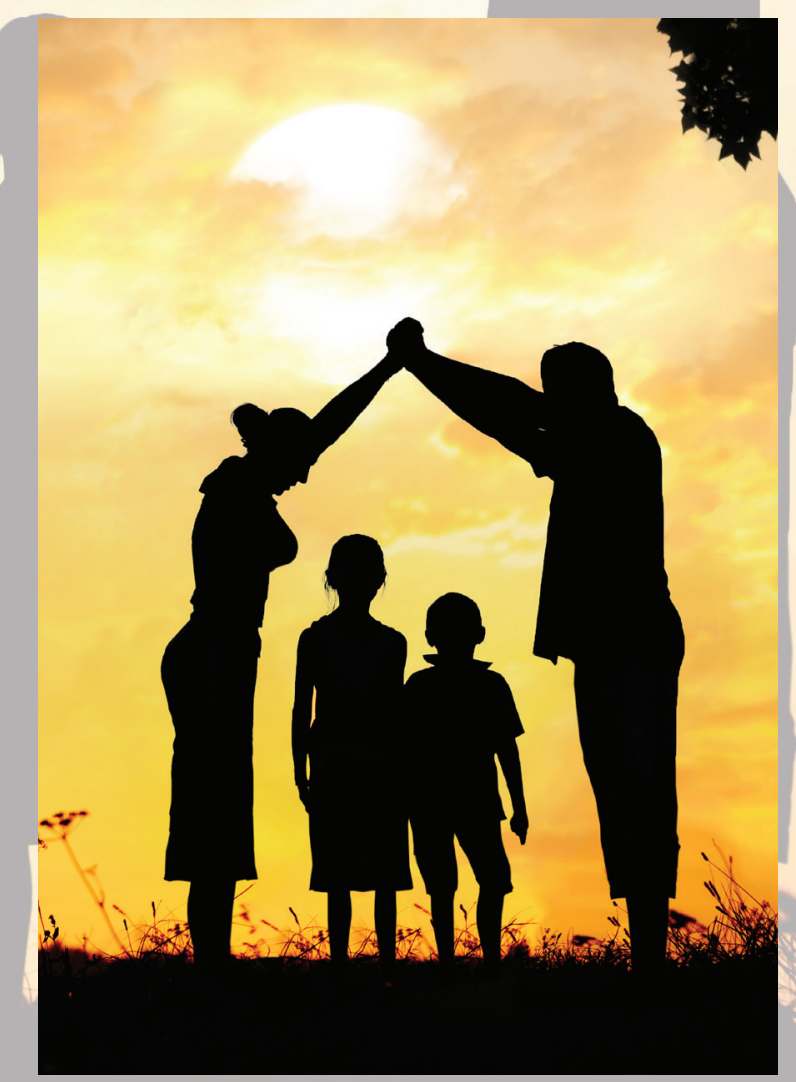

Creado por Skadyfernix - Freepik.com 



\title{
LAS UNIONES CONVIVENCIALES EN LA NUEVA LEGISLACIÓN CIVIL ARGENTINA*
}

\author{
José Vicente Andrade Otaiza \\ Universidad Católica de Colombia
}

\section{Resumen}

La unión convivencial y el reconocimiento de "otros" derechos por fuera del Título III del Código Civil de Vélez es una novedad que introduce el Proyecto de reforma y unificación del Código Civil 2012, en su Libro II, "Familia". Su Título III regula la "unión convivencial", antes — peyorativamente— "unión concubinaria" o "concubinato". El objetivo del artículo es indagar sobre los antecedentes de dicha regulación, para comprender su marco legal, así como precisar el problema entre el principio de autonomía de la voluntad y la noción de orden público o el modo como resuelve la dualidad entre el derecho a no casarse y el derecho a una protección integral de la familia, cualquiera que sea su forma. Se plantea la pregunta: ¿La unión convivencial es el mecanismo idóneo para resolver la tensión social entre el matrimonio y las uniones de hecho, con respeto de principios y valores constitucionales? La posibilidad de que las parejas unidas convivencialmente sean beneficiarias de la protección prevista para la vivienda y estén legitimadas para reclamar indemnización por daños ante la muerte de su pareja, entre otros aspectos, son razones para considerar que hay más de una forma de familia, no solo sustentada en vínculos genéticos, sino también afectivos. Esta consagración no es una creación de los redactores del Proyecto, sino un reconocimiento a las corrientes jurisprudenciales y doctrinarias que, sobre todo después de la reforma constitucional de 1994, proponían la ampliación de derechos a esta estructura familiar y afectiva distinta al matrimonio.

Palabras clave: concubinato, unión convivencial, autonomía de la voluntad, orden público, derechos, matrimonio, responsabilidad, solidaridad.

El autor: docente del área de Derecho Privado, de la Universidad Católica de Colombia. Correo electrónico: jvandrade@ucatolica.edu.co

Recibido: 5 de mayo de 2017 Evaluado: 15 de octubre de 2017 Aceptado: 16 de octubre de 2017

\footnotetext{
El presente artículo formó parte de un proyecto de investigación desarrollado en uno de los cursos del Doctorado en Derecho de la Universidad de Buenos Aíres, en el año 2015. En ese momento se encontraba recién expedido el nuevo Código Civil y Comercial de la Nación argentina, considerado como uno de los más actualizados de toda Iberoamérica.
} 


\title{
CONJUGAL UNIONS IN ARGENTINA'S NEW CIVIL LEGISLATION
}

\author{
José Vicente Andrade Otaiza \\ Universidad Católica de Colombia
}

\begin{abstract}
Domestic unions and the acknowledgment of "other" rights outside of Title III of the Civil Code of Argentina are some of the novelties introduced in "Family," the Second Book of the 2012 Civil Code Reform and Unification Project. Title III regulates the "domestic union," formerly known as "concubinary union" or "concubinage". The purpose of this paper is to investigate the background of said regulation in order to understand its legal framework. It also seeks to identify the problem between the principle of autonomy and the idea of public order, or the duality between the right not to marry and the right to a comprehensive protection of the family: Is domestic union the ideal mechanism to solve the social tension between marriage and de facto unions while respecting constitutional principles and values? The possibility that cohabitating couples will benefit from housing protection and be entitled to compensation for damages resulting from the death of their partner, among other things, are reasons to believe there is more than one type of family, based not only on genetics but also on affectional bonds. This is not a creation of the leaders of the project, but an acknowledgment of the jurisprudence and doctrines that, particularly following the constitutional reform of 1994, proposed extending the rights to this type of family and affective structure, different from marriage.
\end{abstract}

Keywords: concubinage, coexistence, autonomy, public order, rights, marriage, responsibility, solidarity.

About the author: Private Law professor at Universidad Católica de Colombia. E-mail: jvandrade@ ucatolica.edu.co

Received: May 5, 2017; evaluated: October 15, 2017 Accepted: October 16, 2017

\section{Introducción}


El progresivo incremento del número de personas que optan por organizar su vida familiar a partir de las uniones de hecho constituye una constante en todos los sectores sociales y ámbitos de la sociedad contemporánea.

En Argentina, la reforma constitucional de 1994 implicó la aceptación de diversas formas de organización de la familia y ha otorgado efectos jurídicos a las relaciones afectivas que cumplen determinados requisitos como estabilidad, publicidad, permanencia y singularidad, aunque se trate de personas del mismo o diferente sexo.

Desde el punto de vista constitucional, en dichos reconocimientos se encuentran inmersos derechos constitucionales como a tener una familia, la dignidad de la persona, la igualdad, la libertad, la intimidad y la solidaridad familiar.

En esta figura jurídica, es innegable la tensión entre la voluntad concretada en la posibilidad que tienen los particulares de contraer matrimonio o no hacerlo, independientemente de la orientación sexual de la pareja. Dicha tensión también se manifiesta en la voluntad de los particulares en referencia al orden público, evidenciada en el respeto a los valores mínimos de solidaridad. Dichas tensiones se resuelven al reconocer efectos jurídicos a las voluntades de los convivientes — aunque sea de manera algo general - y aceptar que, de conformidad con lo previsto en el Artículo 16 de la Constitución nacional, es posible brindar un tratamiento diferenciado a modelos distintos de familia. ${ }^{1}$

En este trabajo se ilustra la ampliación de derechos a las convivencias de pareja que recoge el Proyecto de reforma de 2012, más allá de lo especificado en el Título III, dedicado a regular la relación entre adultos durante la vigencia y cese de la unión basada en los principios de igualdad, autonomía de la voluntad y protección integral de las familias, entre otros, dado que el derecho le debe dar cabida a todos.

Con base en los antecedentes de normas hoy derogadas como las del Código de Vélez propias del siglo XIX y sus modificaciones posteriores, que nada aportaban a la problemática de las uniones de hecho como las convivenciales, la Ley 26.994 de 2015, actual Código Civil y Comercial de la Nación, inspirado en las pautas para una interpretación sistemática de las normas, en la constitucionalización del derecho privado, en la prioridad que deben tener los valores y las reglas generales

Eduardo A. Zannoni, Marina Mariani de Vidal, Jorge Osvaldo Zunino, Fernando Shina, Gloria Ramos y Aída Kemelmajer de Carlucci, Código Civil y Comercial. Concordado con el régimen derogado y referenciado con legislación vigente (Buenos Aires: Astrea, 2015), 171. 
y en la unificación del derecho civil y comercial en una sola codificación, presenta en materia de personas y familia un régimen más adecuado y acorde con los fenómenos sociales y económicos del siglo XXI; para ello, tiene en cuenta las normas internacionales aplicables.

Por eso, ofrecemos un breve análisis de las instituciones anteriores a la actual normativa y del régimen actual de las uniones convivenciales, enmarcados en una metodología analítica cualitativa.

\section{Antecedentes}

Para la elaboración del Código Civil y Comercial de la Nación se tuvieron como base proyectos de reformas anteriores: ${ }^{2}$

- Proyecto preparado por Juan Antonio Bibliacioni.

- Proyecto de 1936.

- Proyecto redactado bajo la dirección de Jorge Joaquín Llambias (1954).

- Proyecto de unificación de la legislación civil y comercial, proveniente de la Cámara de Diputados de la Nación (1987).

- Proyecto preparado por la Comisión creada por Decreto del Poder Ejecutivo Nacional 468/92.

- Proyecto de la unificación civil y comercial, elaborado por la Comisión Federal de la Cámara de Diputados de la Nación (1993).

- Proyecto de unificación preparado por la comisión creada por Decreto 685/95 del Poder Ejecutivo Nacional (1998).

\subsection{Las uniones de hecho analizadas brevemente por la doctrina}

2 Mariano Otero, Matrimonio, disolución del matrimonio, régimen patrimonial del matrimonio, uniones convivenciales, procesos de familia (Buenos Aires: Estudio, 2015), 18. 
El término unión tiene la ventaja de su consolidación social y jurídica. Abarca una pluralidad de manifestaciones con características similares, pero no idénticas: jóvenes que cohabitan antes de casarse (a modo de prueba); parejas que han decidido mantenerse al margen del matrimonio en forma consciente y voluntaria; uniones de sectores sociales excluidos o vulnerables en los que se trata de una práctica generalizada, etc. ${ }^{3}$

En la legislación argentina vigente hasta principios de agosto de 2015, la unión de hecho no se encontraba regulada, salvo algunos derechos reconocidos en legislaciones especiales y en materia jurisprudencial. ${ }^{4}$ Tradicionalmente, a ese tipo de uniones la doctrina las ha llamado concubinato, "unión de hecho", "unión libre" o "matrimonio aparente". El Código Civil de Vélez desconoce esta forma de organización familiar y ha dado mayor relevancia a temas vinculados a situaciones de vulnerabilidad en la familia y de violencia familiar.

En 2015 se expidió el Código Civil y Comercial de la Nación (CC y C de la N), cuyo Título III, Artículos 509 a 528, reguló las uniones convivenciales, aplicable a relaciones afectivas de carácter singular, público, notorio, estable y permanente de dos individuos que conviven y comparten un proyecto de vida común. Esta modalidad se presenta cuando los sujetos desean convivir, pero no contraer matrimonio con todas las formalidades existentes, lo que crea nuevas situaciones — las bien llamadas uniones de hecho- que no estaban reglamentadas en la legislación; en razón a ello, se llevaron ante los tribunales situaciones de falta de regulación taxativa.

Los legisladores encontraban diversas problemáticas cuando las personas requerían resolver su situación en el evento de ruptura de su unión libre, conflictos que no tenían respuesta uniforme por la jurisprudencia ante la falta de regulación legal, hasta la entrada en vigencia del nuevo Código Civil y Comercial de la Nación.

Debido a la indicada ausencia de normatividad que acotara el fenómeno de las uniones de hecho, cada vez más numerosas, en 2011 la Presidencia de la Nación le encomendó a un grupo de juristas la tarea de diseñar un proyecto para el nuevo Código Civil y Comercial. Esta obra empezó a regir a partir del mes de agosto de 2015 y reemplazó al Código Civil elaborado por Vélez Sarsfield. Dicha normatividad, enfocada desde el paradigma constitucional de los derechos humanos, incorpora

Zannoni, Mariani de Vidal, Zunino, Shina, Ramos y Kemelmajer de Carlucci, Código Civil y Comercial, 171. Jorge Perrino, "Matrimonio y uniones de hecho: diferencias" en Análisis del proyecto de nuevo Código Civil y Comercial 2012, ed. J. N. Lafferrière (Buenos Aires: Universidad Católica de Argentina, 2012), 245-247. 
una propuesta diferenciada del matrimonio, que respeta la autonomía personal de los convivientes, tutela los derechos esenciales de quienes optaron por esta forma de organización familiar ${ }^{5}$ y establece un mínimo de garantías anclado en la responsabilidad familiar.

\subsection{Código Civil de Vélez}

Si bien el Código Civil de Vélez Sarsfield fue acomodándose con el paso del tiempo, mediante algunas reformas parciales, en los comienzos del siglo XXI requirió un ajuste más profundo e integral. Es preciso recordar que ese Código lo terminó de escribir el señor Dalmasio Vélez Sarsfield el 25 de septiembre de 1869 y, mediante la Ley 340 , entró en vigencia el 1 de enero de 1871. Esta obra tuvo gran influencia del derecho continental, pues se fundamentó en los principios liberales del siglo XVIII, cuyas principales fuentes fueron el Código Civil de Chile, el Código de Napoleón, la legislación colonial española que aún estaba vigente en Argentina y el Código francés. ${ }^{6}$ De igual manera lo dice Herrera, ${ }^{7}$ quien esboza una breve reseña acerca de las fuentes que le dieron vida al Código Civil de Vélez.

Luego de varios intentos de reformar el Código de Vélez, en el año 1968 se logró hacerlo de manera parcial con la Ley 17.711, fundamentada en la jurisprudencia del siglo XX; se renovó todo criterio exegético del siglo pasado y se incorporaron soluciones de justicia mediante diversas instituciones, entre ellas, la lesión subjetivaobjetiva y la teoría de la imprevisión, entre otras.

La idea de elaborar un código nuevo desde su estructura, método y contenido, que conservara muchas normas del Código de Vélez, se originó con la presentación de dos proyectos en los años 1987 y 1998, mas no lograron aceptación. Por último, se unificaron el Código Civil y el Código Comercial, lo que constituyó la base del derecho privado. Ello coexiste con leyes especiales que regulan materias específicas y muy especializadas en las dos áreas del derecho privado. El autor citado deja ver su opinión acerca de los códigos completos y autosuficientes, fundados en el exceso de positivismo en los que el intérprete debía ajustarse a repetir las palabras de la ley. Este sistema entró en crisis total a finales del siglo XIX, cuando el Estado

Perrino, "Matrimonio y uniones de hecho", 245.

6 Julio César Capparelli, "El tratamiento de las uniones de hecho en la Argentina (1810-2010)" en Estudios de derecho civil con motivo del bicentenario, dir. Julio Conte-Grand y coord. Gabriel de Reina Tartière (Buenos Aires: El Derecho, 2011), 3-4.

7 Daniel Herrera, "Algunas reflexiones sobre los fundamentos del Código" http://bibliotecadigital.uca.edu.ar/ repositorio/contribuciones/algunas-reflexiones-fundamentos-codigo-herrera.pdf (acceso agosto 19, 2010). 
legal de derecho, apoyado en la ley como la fuente principal del derecho, va siendo reemplazado por un Estado constitucional de derecho, en el que la Constitución es un orden de principios y valores a los que se incorpora un nuevo ordenamiento que otorga igualdad y permite que el sujeto de derecho sea el centro de la regulación jurídica.

El Código Civil argentino originario, anterior al de Vélez, ignoró las relaciones diferentes al matrimonio. En el Código de Vélez, cualquier otra forma de unión era denominada "concubinato" y si quienes la conformaban adquirían bienes en común, eran tratadas en el escenario patrimonial como partes de una sociedad de hecho; con el tiempo, estas uniones fueron adquiriendo derechos, debido a las continuas legislaciones y reformas, como gozar de la obra social, es decir, el cónyuge se beneficia de la pensión de su concubino tras el fallecimiento.

La reforma al Código Civil provocó muchas opiniones sobre las nuevas uniones convivenciales; por ejemplo, para Perrino, ${ }^{8}$ hablar de familia supone un matrimonio como punto de partida, puesto que se refiere a un concepto de singularidad; por eso, considera que las uniones de hecho o "convivenciales" no constituyen nuevas formas de familia, como tampoco son estructuras equiparables a la familia, porque conllevan a vínculos jurídicos de filiación extramatrimonial y de parentesco y la familia solo se constituye a partir del matrimonio y como consecuencia de este.

\subsection{Derechos de las personas en uniones de hecho}

La tratadista Riba, ${ }^{9}$ en su análisis y seguimiento sobre los derechos que les asisten a quienes han decidido conformar una unión de hecho, considera que esas relaciones antiguamente denominadas "concubinatos" siguen siendo una situación de hecho. Al referirse al tema sucesoral, el cónyuge tendría la oportunidad de ser reconocido como heredero si hubiera contraído nupcias treinta días antes del deceso del causante. ${ }^{10}$ Con ello habría sido admitido a los fines provisionales, a la posibilidad de ser beneficiario de la obra social de su compañero y al otorgamiento de una pensión

Perrino, "Matrimonio y uniones de hecho", 249.

9 María Andrea Riba, "La legitimación del concubino para solicitar resarcimiento por daños y perjuicios" en Anuario de derecho civil de la Facultad de Derecho y Ciencias Sociales. Tomo XI, ed. Luis Moisset de Espanés (Buenos Aires: Alveroni Editores, 2011), 108.

10 Argentina, Congreso de la Nación, Ley 340, "Código Civil" (Buenos Aires: RN No. 1863/69, 25 de septiembre de 1869), art. 3575. 
derivada: ${ }^{11}$ se habría aceptado su legitimidad para recibir una indemnización por muerte en la legislación laboral ${ }^{12}$ y su derecho a continuar la locación iniciada por el concubino. ${ }^{13}$

Una situación particular se presenta en cuanto al derecho de daños. Se ha debatido en doctrina y jurisprudencia si una persona se encuentra habilitada para reclamar el resarcimiento por la muerte del concubino. Entre los daños que podría reclamar están:

\subsubsection{Daños patrimoniales}

Al no existir relación con la víctima, porque no se reconoció esa relación como legítima, la legislación de Vélez le exigía al concubino la materialización de todos los elementos necesarios para que se configurara "una responsabilidad civil"; así, el concubino tendría derecho a resarcimiento de los daños.

Mientras el concubinato no estuvo dentro del marco normativo, no se le otorgó legitimidad al concubino sobreviviente para reclamar la reparación del daño por la ausencia de su concubino. Mas la realidad de los hechos fue en aumento, hasta que el Legislador debió habilitar al sobreviviente para solicitar dicha reparación, ${ }^{14}$ siempre y cuando quien reclamara acredite el daño causado por la muerte.

Esa discusión confrontó dos tesis sobre el daño resarcible: la clásica, que condiciona el resarcimiento del daño a que el menoscabo recaiga sobre un interés legítimo, derecho subjetivo o bien jurídicamente protegido y sostiene que el interés lesionado debe ser tutelado por la ley. La otra tesis afirma que para que el daño sea resarcible

11 Argentina, Congreso de la Nación. Ley 24.241, "Sistema integrado de jubilaciones y pensiones" (Buenos Aires: Boletín Oficial No. 27745, 18 de octubre de 1993), art. 53.

12 Argentina, Presidencia de la Nación, Ley 21.297, "Integración de comisiones para el estudio y elaboración de proyectos de ley-modificación de la Ley 20.744 y derogación de la Ley 20695" (Buenos Aires: Boletín Oficial, 29 de abril de 1976), art. 248.

13 Argentina, Presidencia de la Nación, Ley 21.342, "Normalización de locaciones urbanas. Régimen que reemplaza al instituido por la Ley 20.625 y sus prórrogas" (Buenos Aires: Boletín Oficial No. 23.437, 30 de junio de 1976), art. 10.

14 Puede verse la jurisprudencia federal No. 1, Sala I, en autos: "Gómez, Rebeca Gabriela c. Estado Nacional Minist. de Defensa; Est. Mayor del Ejército s/Accidente en el ámbito militar y F. Seguridad", del 14 de marzo de 2000; Causa No. 3309/98; "Chávez de Serrichio Susana C. C. Estado Nacional —Minist. del InteriorPrefectura Naval s/Accidente en el ámbito militar y F. Seguridad", exp. No. 1046/99 del 09 de noviembre de 2000; "Lagraña, Marta Susana y otros c. Estado Nacional —Minist. Salud Acc. Soc.—Secret. Salud y otros s/Daños y perjuicios varios", exp. No. 11.018/95 del 1 de octubre de 1998; en ellos se admite la reparación del daño material sufrido por la concubina y se niega el daño moral reclamado. 
basta la lesión a un simple interés, siempre que no sea ilegítimo o violatorio de la moral o del orden público.

En este sentido, la jurisprudencia expresó que la legitimación del conviviente para efectuar el reclamo se originaba desde su condición de simple damnificado por el hecho ilícito que generaba una obligación de reparación, en virtud de lo dispuesto en los Artículos 1069, 1079 y 1109 del Código Civil de Vélez. ${ }^{15}$ De tal modo, la acción de indemnización podría ser intentada en derecho propio cuando se acreditara su lesión a un interés propio, a raíz del cual se determinara un detrimento patrimonial.

\subsubsection{Daño moral}

En materia de daño moral, el propósito en el Código de Vélez fue resarcir el daño de la víctima, quien debía el perjuicio; empero, la existencia de la relación concubinaria no fue elemento indispensable para que se reconociera una indemnización.

El concubino estaba habilitado para reclamar los daños y perjuicios por la muerte de su compañero bajo los términos del Artículo 1079 del Código Civil de Vélez, cuyo texto original indicaba: "La obligación de reparar el daño causado por un delito existe, no sólo respecto de aquel a quien el delito ha damnificado directamente, sino respecto de toda persona, que por él hubiese sufrido, aunque sea de una manera indirecta".

15 "El daño comprende no sólo el perjuicio efectivamente sufrido, sino también la ganancia de que fue privado el damnificado por el acto ilícito, y que en este código se designa por las palabras 'pérdidas e intereses'. Los jueces, al fijar las indemnizaciones por daños, podrán considerar la situación patrimonial del deudor, atenuándola si fuere equitativo; pero no será aplicable esta facultad si el daño fuere imputable a dolo del responsable (Párrafo incorporado por art. $1^{\circ}$ de la Ley $N^{\circ} 17.711$ B.O. 26/4/1968. Vigencia: a partir del $1^{\circ}$ de julio de 1968)". Argentina, Congreso de la Nación, Ley 340, art. 1069.

"La obligación de reparar el daño causado por un delito existe, no sólo respecto de aquel a quien el delito ha damnificado directamente, sino respecto de toda persona, que por él hubiese sufrido, aunque sea de una manera indirecta". Argentina, Congreso de la Nación, Ley 340, art. 1079.

"Todo el que ejecuta un hecho, que por su culpa o negligencia ocasiona un daño a otro, está obligado a la reparación del perjuicio. Esta obligación es regida por las mismas disposiciones relativas a los delitos del derecho civil.

Cuando por efecto de la solidaridad derivada del hecho uno de los coautores hubiere indemnizado una parte mayor que la que le corresponde, podrá ejercer la acción de reintegro (Párrafo incorporado por art. $1^{\circ}$ de la Ley No 17.711 B.O. 26/4/1968. Vigencia: a partir del $1^{\circ}$ de julio de 1968)". Argentina, Congreso de la Nación, Ley 340, art. 1109. 


\subsection{La legitimación del concubino para solicitar resarcimiento en el Código de Vélez}

Se exigía que el interés del concubino fuera suficientemente estable y cierto y que el daño a resarcir fuera acreditado, de manera que el solicitante debía documentar el daño patrimonial causado por la muerte de su compañero.

El Artículo 1078 del Código Civil de Vélez disponía:

La obligación de resarcir el daño causado por los actos ilícitos comprende, además de la indemnización de pérdidas e intereses, la reparación del agravio moral ocasionado a la víctima. La acción por indemnización del daño moral sólo competerá al damnificado directo; si del hecho hubiere resultado la muerte de la víctima, únicamente tendrán acción los herederos forzosos.

Una primera lectura de este Artículo nos lleva a descartar la legitimación del concubino para acceder a un resarcimiento, toda vez que no reviste la calidad de heredero en la sucesión de su compañero.

Se puede notar que la jurisprudencia y la doctrina han negado al concubino el derecho a acceder al resarcimiento del daño moral por el fallecimiento de su compañero, bien sea por aplicar de manera estricta el Artículo 1078 o por resaltar la inexistencia del derecho subjetivo que lo ampare para reclamar sus derechos de concubinos, pues no hay un vínculo legal dotado de efectos jurídicos.

La Suprema Corte de Justicia ha sostenido que la relación de concubinato no tiene notas de permanencia ni puede ser asimilada al matrimonio y que deben contemplarse las situaciones particulares. En este caso, la concubina puede heredar a la hija común habida con el concubino, pero no accede a la indemnización por daños por el fallecimiento de este. ${ }^{16}$

En idéntica dirección, la jurisprudencia ha dicho que quien mantuviera una relación de concubinato con la víctima no tiene calidad de heredero en la sucesión de su compañero.

16 Suprema Corte de Justicia, Sentencia de 14 de septiembre de 2009, causa C. 100.285, R. A. H. contra Kelly, Santiago y otros. Daños y perjuicios. Recurso extraordinario de inaplicabilidad de ley. 


\section{Nuevo Código Civil y Comercial de la Nación}

Para dar lugar al análisis de la institución, es preciso revisar los aspectos generales que fueron tenidos en cuenta por el Legislador argentino para regular las uniones convivenciales.

\subsection{Aspectos sociales}

Herrera 17 "comenzó con un vistazo a toda la fundamentación sobre la cual se llevó a cabo la nueva codificación. Encontró que, al legislar sobre las uniones convivenciales, se obtuvo una reforma con tendencia humanista, es decir, que reconoce que las relaciones afectivas de hecho constituyen nuevas formas de organización familiar. Se fundamentó en la necesidad de reconstruir la coherencia entre el sistema de derechos humanos y el derecho argentino, para incluir en la legislación moderna todas las formas de organización familiar que se han venido conformando en la sociedad argentina. Cabe anotar que la reforma estuvo precedida de un escenario en el que se permitió la participación de personas con distintas visiones de la integración de la familia, sin excluir a quienes desean vivir de manera diferente a la tradicional.

Un fenómeno que se fue presentando con mayor intensidad y que se hizo notorio en el cotidiano vivir fue el de vivir en pareja sin casarse, cada vez más marcado en las clases pobres y marginales. Con gran sorpresa, a medida que transcurrió el tiempo, esta figura se observó en todos los estratos sociales. Las clases medias han venido aceptando las uniones convivenciales con más receptividad y las estadísticas aumentan en forma representativa.

Molina de Juan ${ }^{18}$ muestra las cifras "del último censo: del total de la población casada y en pareja durante catorce años y más (16.703.000), 10.222.566 personas (61,20 \%) están unidas en matrimonio, mientras 6.480 .434 (un 38,80 \%) conviven sin haber celebrado nupcias.

Para dar solución al problema y al fenómeno social originado en la convivencia entre parejas sin que exista formalidad alguna, se propuso, entre otras alternativas, el proyecto de la reforma al Código Civil de Vélez Sarsfield en 2012.

Herrera, "Algunas reflexiones sobre los fundamentos del Código".

18 Mariel Molina de Juan, "Las uniones convivenciales en el derecho proyectado argentino. ¿Será lo mismo casarse que no casarse?", Lumen, Revista de la Facultad de Derecho de la Universidad Femenina del Sagrado Corazón 9 (2015): 103, http://www.unife.edu.pe/publicaciones/revistas/derecho/lumen_9/lumen_9.html 


\subsection{Aspectos jurídicos}

El Artículo 509 del Código Civil y Comercial de la Nación, Ley 26.994 de 2014, define la unión convivencial: "[...] la unión basada en relaciones afectivas de carácter singular, pública, notoria, estable y permanente de dos personas que conviven y comparten un proyecto de vida común, sean del mismo o de diferente sexo". Para dar paso a esta definición, los redactores del Código se fundamentaron en los estamentos constitucionales de los derechos humanos e incorporaron una propuesta normativa que diferencia el matrimonio de las otras formas de uniones, en busca de respetar la autonomía de la voluntad y de proteger los derechos esenciales de quienes optaron por esta forma de convivencia. Propone una regulación parcial y equilibrada que propicia la celebración de convenios para acordar los efectos de la vida en común, pero fija un núcleo mínimo de garantías fundamentado en la responsabilidad familiar, que se establece como régimen primario inderogable.

El derecho que regula las relaciones familiares debe ocuparse del derecho familiar en sí mismo y su interpretación está administrada por los mismos principios que inspiran el derecho familiar constitucional. Esta nueva legislación se ha encargado de la filosofía que considera que el matrimonio, la familia y la sexualidad humana son realidades que no dependen de factores objetivos o naturales, sino de planteamientos subjetivos, esto es, ideologías individuales y colectivas basadas en la voluntad.

\section{Aspectos metodológicos}

Perrino ${ }^{19}$ afirma que este proyecto se fundamentó en aspectos valorativos y metodológicos. Entre los valorativos están: i) que sea un código con identidad cultural latinoamericana; ii) constitucionalización del derecho privado; iii) código de la igualdad; iv) código basado en un modelo no discriminatorio; v) código de los derechos individuales y colectivos; vi) código para una sociedad multicultural, y vii) código para la seguridad jurídica en las transacciones comerciales.

Entre los metodológicos resaltan: i) amplia participación y discusión de la doctrina; ii) consensos y decisiones valorativas, y iii) un título preliminar y partes generales sobre las instituciones que regulan la redacción de las normas del sistema.

19 Perrino, "Matrimonio y uniones de hecho", 268. 
El anterior análisis se llevó a cabo con la finalidad de incorporar el derecho privado argentino al bloque cultural y latinoamericano, con el propósito de legislar con los mismos criterios de la región.

\section{Aspectos ideológicos}

Previo el análisis de la normativa proyectada, se hace necesario precisar el marco ideológico que inspiró el proyecto de reforma que desarrolla la pretendida nueva regulación jurídica de las relaciones de familia y las diferencias entre concubinato, unión de hecho o unión convivencial y el matrimonio.

Para Perrino, ${ }^{20}$ el enfoque que la legislación ha dado al matrimonio como única forma de unión familiar obedece a la secularización y al positivismo en el que se ha fundamentado el Legislador para conceptualizarlo en un marco diferente al de la sexualidad, pues se entiende el matrimonio como un consorcio entre varón y mujer en cuanto tales y en la totalidad de su ser masculino y femenino, no centrado en la sexualidad. En cambio, hoy por hoy, en las relaciones de facto, se anteponen los intereses individuales como mecanismo de desarrollo de la personalidad, lo que lleva a que una familia se conforme sin una unión matrimonial y alejada de la concepción de la familia tradicional.

En este escenario, las prácticas de la conformación de las uniones de hecho o convivenciales se desarrollan sin importar si media o no el matrimonio, porque ya no se considera que la procreación normal sea elemento indispensable dentro de los nuevos conceptos de matrimonio, familia o uniones de hecho.

Esas nuevas formas de familia representan lo que los directores del anteproyecto del Código Civil y Comercial denominaron sociedad multicultural, lo que se basa en el principio de la igualdad, la libertad, el derecho a la vida familiar, la dignidad de la persona, la intimidad y la solidaridad familiar. Todos estos derechos deben conjugarse y articularse de manera armonizada y coherente con el régimen matrimonial.

Con este fondo se reconocen y se legisla sobre las "uniones convivenciales", porque ellas se definen desde el punto de vista de la convivencia, es decir, compartir la vida en pareja a partir del afecto -independiente de la orientación sexual de sus integrantes-y en aparente matrimonio. Con ello, el nuevo Código Civil y Comercial

20 Perrino, "Matrimonio y uniones de hecho", 260 
de la Nación buscó darle estructura social y jurídica a un fenómeno que abarca una pluralidad de manifestaciones similares, pero no idénticas.

\section{Aspectos normativos}

Otero ${ }^{21}$ refiere que en el cuerpo normativo del antiguo Código de Vélez, fue necesario insertar algunas normas que se refirieran al concubinato (Leyes 17.711, $23.264,20.798,23.515)$. Se incluyeron los servicios de guarda de gametos o tejidos reproductivos según la mejor tecnología, dirigida a aquellas personas que no deseen un embarazo inmediato, sino materializarlo en un futuro. Respecto a la seguridad social, se legisló sobre varios temas que se encontraban sin regulación normativa:

- Ley 26.529: sobre la incapacidad del paciente o la imposibilidad de comprender la información a causa de su estado físico o psíquico.

- Ley 24.417, última parte del Artículo 1: violencia intrafamiliar.

- Ley 24.374, Artículo 2: derecho de sucesión para aquellas personas que convivieron con el causante.

- Ley 24.241, Artículo 53: los beneficiarios de la pensión del fallecido.

- Ley 24.193, Artículo 21: en caso de muerte natural, los llamados a decidir sobre la ablación de sus órganos o a conocer la finalidad de los mismos.

- Ley 23.570: derecho a pensión en caso de convivencia en aparente matrimonio.

— Ley 21.388: pensiones, causales y pérdida y extinción de beneficio.

- Decreto PEN No.1450/2005: previsión social, pensiones asistenciales, pensiones no contributivas a la vejez, fallecimiento del titular y derecho a pensión, en los términos del Artículo 9 de la Ley 13.478, del cónyuge supérstite o concubino.

21 Otero, Matrimonio, disolución del matrimonio, 217. 
Lo anterior refleja que, desde tiempo atrás, la legislación argentina necesitaba un entramado normativo que reuniera todos los aspectos que involucran las uniones convivenciales. Los derechos y deberes que surgen de la unión convivencial son los siguientes:

\subsection{La adopción conjunta ${ }^{22}$}

Una posibilidad que brinda el proyecto aprobado el 28 de noviembre de 2013 se refiere a la adopción conjunta por personas unidas convivencialmente, es decir, aquellas que cumplan con la descripción y los requisitos previstos en los Artículos 509 y 510 del Título III del Libro II del Código Civil y Comercial de la Nación. Así como lo afirma el Artículo 510 del CCN:

Artículo 510. Requisitos. El reconocimiento de los efectos jurídicos previstos por este Título a las uniones convivenciales requiere que:

a) los dos integrantes sean mayores de edad;

b) no estén unidos por vínculos de parentesco en línea recta en todos los grados, ni colateral hasta el segundo grado;

c) no estén unidos por vínculos de parentesco por afinidad en línea recta;

d) no tengan impedimento de ligamen ni esté registrada otra convivencia de manera simultánea;

e) mantengan la convivencia durante un período no inferior a dos años.

El texto aprobado establece lo siguiente: "El niño, niña o adolescente puede ser adoptado por un matrimonio, por ambos integrantes de una unión convivencial o por una única persona", ${ }^{23}$ a lo que se agrega lo previsto en el Artículo 602: "Las personas casadas o en unión convivencial pueden adoptar sólo si lo hacen conjuntamente". Como se dijo, la jurisprudencia ya se había expresado en este punto y declaró en varios precedentes la inconstitucionalidad del Artículo 312 del CC de Vélez — que impedía la adopción por dos personas que no fueran cónyuges—a la

\footnotetext{
Otero, Matrimonio, disolución del matrimonio, 241.

23 Argentina, Congreso de la Nación, Ley 26.994, "Código Civil y Comercial de la Nación" (Buenos Aires: Boletín Oficial No. 32.985, 8 de octubre de 2014), art. 599.
} 
luz de los tratados de derechos humanos; la Convención de los derechos del niño; el concepto amplio de familia que emana del Artículo 14 bis de la Constitucional nacional y el principio de autonomía de la voluntad expresado en el Artículo 19 de la misma Carta Magna.

\subsection{La protección de la vivienda como derecho humano}

En materia de derecho a la vivienda, la reforma produjo un cambio radical de pensamiento respecto a la regulación vigente del "bien familia" instaurado por la Ley 14.394 de 1954. Conforme sendos tratados internacionales ratificados por la Nación argentina, el acceso a la vivienda es un derecho humano. La protección que se le brinda en el CC de la Nación va más allá de tener o no tener una familia, pues se reconoce y autoriza también a la persona "sola" a constituir como "bien de familia" la vivienda de su titularidad.

En lo que aquí interesa —las convivencias de parejas_-, el proyecto asienta la posibilidad de que los beneficiarios de la afectación sean: "a) el propietario constituyente, su cónyuge, su conviviente, sus ascendientes o descendientes [...]". ${ }^{24}$ Asimismo, se permite que todos los condóminos, incluidos los convivientes, tengan o no hijos en común, puedan constituir el bien de familia. ${ }^{25}$ Recordemos que la jurisprudencia ya había avanzado, pero limitó esta extensión a las parejas de condóminos que tuvieran hijos, por aplicación del principio de no discriminación entre los matrimoniales y extramatrimoniales.

\subsection{Legitimación para reclamar indemnización por daño patrimonial y daño extrapatrimonial}

El proyecto recoge los avances doctrinarios y jurisprudenciales con miras a ampliar el grupo de personas legitimadas para reclamar la indemnización por daños patrimoniales y extrapatrimoniales en caso de muerte. Respecto al primero de estos, ya en 1995, la Cámara Nacional Civil en pleno había reconocido el daño material por la muerte del conviviente y, sobre el segundo, también existían antecedentes jurisprudenciales que, tras declarar la inconstitucionalidad del Artículo 1078 del CC de Vélez, habían concedido daño moral al conviviente a pesar de no ser —ni hoy ni

\footnotetext{
24 Argentina, Congreso de la Nación, Ley 26.994, 246

25 Argentina, Congreso de la Nación, Ley 26.994, 245.
} 
en el texto del CC y de C- heredero forzoso ${ }^{26}$ Con estos lineamientos, la reforma del Artículo 1741 define que tendrán legitimación para reclamar indemnización de las consecuencias no patrimoniales: "[... el el damnificado directo. Si del hecho resulta su muerte o sufre gran discapacidad, también tienen legitimación a título personal, según las circunstancias, los ascendientes, los descendientes, el cónyuge y quienes convivían con aquél recibiendo trato familiar ostensible". Claramente, el conviviente entraría en esta última opción prevista en la ley; en este caso, no es necesario el cumplimiento de los requisitos para ser considerada una unión convivencial.

Por su parte, al regular el alcance de la indemnización material por muerte, el Artículo 1745 dispone:

En caso de muerte, la indemnización debe consistir en: a) los gastos necesarios para asistencia y posterior funeral de la víctima. El derecho a repetirlos corresponde a quien los paga, aunque sea en razón de una obligación legal; b) lo necesario para alimentos del cónyuge, del conviviente, de los hijos menores de veintiún años de edad con derecho alimentario, de los hijos incapaces o con capacidad restringida, aunque no hayan sido declarados judicialmente.

\subsection{El concepto}

Como se ha indicado, las uniones convivenciales están basadas en relaciones afectivas de carácter singular, público, notorio, estable y permanente de dos personas que conviven y comparten un proyecto de vida común, sean del mismo o de diferente sexo. En la definición de la unión convivencial que trae el CC y C se hace especial énfasis en la existencia de un lazo afectivo entre los convivientes. Leonardo Pucheta ${ }^{27}$ explica que, a diferencia del dato genético, el afecto rara vez aparece mencionado en las normas jurídicas referidas a la familia. No obstante, los operadores del derecho han empezado a pensar que, en numerosas ocasiones, las relaciones familiares deberían moverse más en el ámbito de la afectividad que en el de los lazos biológicos o genéticos o en el de la regulación legal única. De allí que un concepto que parecía pertenecer solo al derecho brasileño (la afetividade)

26 María V. Pellegrini, "El convenio regulador del divorcio en el Código Civil y Comercial" http://colectivoderechofamilia.com/wp-content/uploads/2015/06/MVP-El-convenio-regulador-del-divorcio-en-el-CódigoCivil-y-Comercial.pdf (acceso octubre 31, 2014).

27 Leonardo Pucheta, "Los cambios en el derecho de familia en el nuevo Código Civil" http://centrodebioetica. org/2014/10/3148/\#_ftnrefl (acceso octubre 31, 2014). 
se haya trasladado a otros ordenamientos en los que ya se comienza a hablar del "parentesco social afectivo", para reflejar la relación que surge entre personas que, sin ser parientes, se comportan entre ellos a modo y semejanza. Se ha producido, entonces, lo que ha dado en llamarse "desencarnación", o sea, el debilitamiento del elemento carnal o biológico en beneficio del elemento psicológico y afectivo.

Este factor socioafectivo da lugar a pensar e incursionar en la existencia de familias no matrimoniales con incidencia en variados aspectos del derecho de familia, como el derecho de daños por razón de la existencia del lazo afectivo; esto comprende un aspecto que considero bastante amplio como para que el derecho de las personas extienda sus lazos sobre nuevas instituciones jurídicas, por ejemplo, los derechos derivados de la crianza.

\subsection{Formalidades}

El Artículo 510 del CC y C de la Nación indica:

"Artículo 510. Requisitos. El reconocimiento de los efectos jurídicos previstos por este Título a las uniones convivenciales requiere que:

a. los dos integrantes sean mayores de edad;

b. no estén unidos por vínculos de parentesco en línea recta en todos los grados, ni colateral hasta el segundo grado;

c. no estén unidos por vínculos de parentesco por afinidad en línea recta;

d. no tengan impedimento de ligamen ni esté registrada otra convivencia de manera simultánea;

e. mantengan la convivencia por un período superior a dos años.

Para que la unión convivencial se configure y produzca los efectos jurídicos que la ley les reconoce, es preciso que se cumplan los requisitos transcritos, que son similares a los que consagra la legislación argentina como impedimentos para contraer matrimonio. 
Para los fines probatorios y de publicidad, prevé el Artículo 511 del CC y C de la Nación que dicha unión convivencial y su extinción deben anotarse en un registro especial creado para el efecto, a petición de ambos convivientes. La prueba de la unión convivencial, como lo indica el Artículo 512 del CC y C de la Nación, se acredita con la certificación o el documento de su inscripción en el Registro especial de convivientes.

\subsection{Los pactos de convivencia}

Los convivientes pueden celebrar pactos o convenios por escrito acerca de los efectos que producirá la unión convivencia ${ }^{28}$ como una manifestación de la autonomía de la voluntad. No obstante, dichos pactos están limitados por la regulación expresa de norma en contrario que, en general, tienden a resguardar aspectos esenciales de esa relación, como no suministrar asistencia durante la convivencia (art. 519) ${ }^{29}$ no contribuir a en los gastos del hogar en proporción a sus recursos (art. 455 y 520$)^{30}$ y no responder frente a terceros de manera solidaria por las obligaciones que uno de ellos haya contraído para solventar las necesidades ordinarias del hogar (arts. $455,461$ y 421$).{ }^{31}$

Asimismo, se protege la vivienda familiar en caso de cese de la unión convivencial y se obliga a que el uso del inmueble que fuera su sede sea atribuido a uno de los convivientes cuando tenga a su cargo el cuidado de menores de edad, cuando uno de los convivientes tenga capacidad restringida o discapacidad o cuando acredite la extrema necesidad de una vivienda y la imposibilidad de procurársela en forma inmediata. En estos eventos, pueden celebrarse pactos convivenciales contrarios a los supuestos de hecho indicados (art. 526). ${ }^{32}$

La atribución de la vivienda como pacto convivencial será por un plazo máximo de dos años, durante el cual el inmueble no podrá ser enajenado sin el acuerdo expreso de ambos convivientes, no puede ser objeto de partición ni de liquidación patrimonial; para proteger a los terceros, dichos pactos deben publicarse en el registro de convivientes y del inmueble.

\footnotetext{
Alberto J. Bueres, dir., Código Civil y Comercial de la Nación: analizado, comparado y concordado (Buenos Aires: Hammurabi, 2015), 381.

Argentina, Congreso de la Nación, Ley 26.994, art. 519.

Argentina, Congreso de la Nación, Ley 26.994, arts. 455 y 520.

Argentina, Congreso de la Nación, Ley 26.994, arts. 455,461 y 521.

Argentina, Congreso de la Nación, Ley 26.994, art. 526.
} 
Cuando la unión convivencial cesa por la muerte de uno de los convivientes (art. 527), ${ }^{33}$ el otro gozará de un derecho real de habitación gratuito y temporal, máximo de dos años, sobre el inmueble de propiedad del causante que constituyó el último hogar familiar; para que ese derecho se mantenga, el inmueble no debe haber sido compartido en condominio con otras personas, pues los derechos de estos terceros no pueden resultar afectados por los de la situación de hecho que comporta la convivencia.

Por último, los convivientes pueden pactar la forma como se distribuirán los bienes (art. 528) ${ }^{34}$ que adquirieron, una vez cese la unión convivencial. Si no acordaron algo, cada conviviente conservará lo que obtuvo a su nombre, aunque sea posible atenuar el rigor de la disposición, al recurrir a instituciones jurídicas como el enriquecimiento sin causa, la simulación, la demostración de la efectividad de los aportes, etc.

Debe dejarse claro, eso sí, que los pactos son modificables durante la existencia de la unión, se rescinden por acuerdo de ambos y el cese de la convivencia implica la extinción de pleno derecho de los efectos de los pactos para el futuro. Para resultar oponibles a terceros, es necesario su registro.

\section{Conclusiones}

En materia de relaciones de familia, el Libro II del Código Civil y Comercial de la Nación muestra cambios y novedades. Entre las segundas se cuentan las uniones convivenciales, respecto a las que no existía antecedente legal en Argentina, a pesar de que la realidad social exigía reconocimientos legales desde hace considerable tiempo.

El mayor desafío para el Código Civil residía en la manera de regular las uniones convivenciales y, dada la tensión social, mantener una adecuada diferencia con el matrimonio, pues se trata de dos formas familiares diversas. En una, la autonomía de la voluntad es el eje central, pero requiere ser compensada con la cuota de solidaridad que impone toda relación familiar; en la otra, la obligatoriedad en la regulación funciona como seguro del compromiso legal asumido, pues las obligaciones implican beneficios. Cada forma familiar tiene sus beneficios y sus cargas.

33 Argentina, Congreso de la Nación, Ley 26.994, art. 527.

34 Argentina, Congreso de la Nación, Ley 26.994, art. 528. 
Con la regulación legal de las uniones convivenciales se dio previsibilidad a las relaciones familiares, circunstancia que no satisface un sistema jurídico de tipo abstencionista, en el que solo se reconoce la forma tradicional de familia.

La asistencia debida es mutua y recíproca, obligatoria solo durante la convivencia y se funda en el derecho básico y esencial, propio de un proyecto de vida en común.

La contribución a los gastos del hogar y la responsabilidad por las deudas frente a terceros se impone a ambos convivientes en los mismos términos que a los cónyuges, por la condición común de modelos familiares, ambos válidos, respetables y signados por pautas mínimas de solidaridad familiar.

Una vez establecidas las relaciones familiares, surge para sus miembros una cuota de responsabilidad y solidaridad familiar que impide desentenderse de ciertos aspectos básicos. En el Código Civil se regula un mínimo de derechos al constituirse la unión convivencial, que puede aumentarse por pactos entre los convivientes. Dichos derechos corresponden a: i) asistencia durante la convivencia; ii) contribución a los gastos del hogar; iii) responsabilidad por las deudas frente a terceros, y iv) protección a la vivienda familiar.

\section{Referencias}

Argentina, Congreso de la Nación. Ley 24.241, "Sistema integrado de jubilaciones y pensiones". Buenos Aires: Boletín Oficial No. 27745, 18 de octubre de 1993.

Argentina, Congreso de la Nación. Ley 26.994, "Código Civil y Comercial de la Nación". Buenos Aires: Boletín Oficial No. 32.985, 8 de octubre de 2014.

Argentina, Congreso de la Nación. Ley 340, "Código Civil". Buenos Aires: RN No. 1863/69, 25 de septiembre de 1869.

Argentina, Presidencia de la Nación. Ley 21.297, "Integración de comisiones para el estudio y elaboración de proyectos de ley-modificación de la Ley 20.744 y derogación de la Ley 20695". Buenos Aires: Boletín Oficial, 29 de abril de 1976.

Argentina, Presidencia de la Nación. Ley 21.342, "Normalización de locaciones urbanas. Régimen que reemplaza al instituido por la Ley 20.625 y sus prórrogas". Buenos Aires: Boletín Oficial No. 23.437, 30 de junio de 1976.

Bueres, Alberto J., dir. "Código Civil y Comercial de la Nación: analizado, comparado y concordado. Buenos Aires: Hammurabi, 2015. 
Capparelli, Julio César. "El tratamiento de las uniones de hecho en la Argentina (1810-2010)" en Estudios de derecho civil con motivo del bicentenario, dirigido por Julio Conte-Grand y coordinado por Gabriel de Reina Tartière, 311-332. Buenos Aires: El Derecho, 2011.

Herrera, Daniel. "Algunas reflexiones sobre los fundamentos del Código". http://bibliotecadigital.uca.edu.ar/repositorio/contribuciones/algunas-reflexiones-fundamentoscodigo-herrera.pdf (acceso agosto 19, 2010).

Molina de Juan, Mariel. "Las uniones convivenciales en el derecho proyectado argentino. ¿Será lo mismo casarse que no casarse?". Lumen, Revista de la Facultad de Derecho de la Universidad Femenina del Sagrado Corazón 9 (2015): 99-110, http://www.unife.edu. pe/publicaciones/revistas/derecho/lumen_9/10.pdf

Otero, Mariano. Matrimonio, disolución del matrimonio, Régimen patrimonial del matrimonio, Uniones convivenciales, procesos de familia. Buenos Aires: Estudio, 2015.

Pellegrini, María V. "El convenio regulador del divorcio en el Código Civil y Comercial". http://colectivoderechofamilia.com/wp-content/uploads/2015/06/MVP-El-convenioregulador-del-divorcio-en-el-Código-Civil-y-Comercial.pdf (acceso octubre 31, 2014).

Perrino, Jorge. "Matrimonio y uniones de hecho: diferencias" en Análisis del proyecto de nuevo Código Civil y Comercial 2012, editado por J. N. Lafferrière, 245-270. Buenos Aires: Universidad Católica de Argentina, 2012.

Pucheta, Leonardo. "Los cambios en el derecho de familia en el nuevo Código Civil". http:// centrodebioetica.org/2014/10/3148/\#_ftnrefl (acceso octubre 31, 2014).

Riba, María Andrea. "La legitimación del concubino para solicitar resarcimiento por daños y perjuicios" en Anuario de derecho civil de la Facultad de Derecho y Ciencias Sociales. Tomo XI, editado por Luis Moisset de Espanés, 101-110. Buenos Aires: Alveroni Editores, 2011.

Suprema Corte de Justicia. Sentencia de 14 de septiembre de 2009, causa C. 100.285, R. A. H. contra Kelly, Santiago y otros. Daños y perjuicios. Recurso extraordinario de inaplicabilidad de ley.

Zannoni, Eduardo A., Marina Mariani de Vidal, Jorge Osvaldo Zunino, Fernando Shina, Gloria Ramos y Aída Kemelmajer de Carlucci. Código Civil y Comercial. Concordado con el régimen derogado y referenciado con legislación vigente. Buenos Aires: Astrea, 2015. 7 